\title{
Drug output slows in 2006
}

Stacy Lawrence

Productivity continued to decline, with a total of only 18 new molecular entities approved, just four of which were biologics. On average for 2004-2006, the 15 largest pharmaceutical firms garnered 19 new product

approvals, compared with 26 for biotech. With the drop in productivity,

\section{Biotech and big pharma productivity}

Pharma's average R\&D spending increased to about $\$ 7$ billion per new molecular entity (NME), whereas biotech's jumped to $\sim 2$ billion.

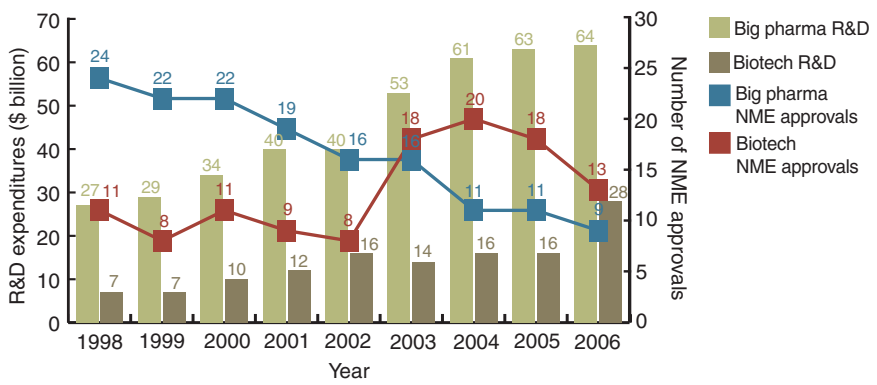

Big pharma defined as 15 largest pharmaceutical companies by market cap. Source Ernst \& Young; Nature Reviews Drug Discovery

\section{Geographic origin of FDA applicants}

More than one-third of clinical investigations are now done outside the US.

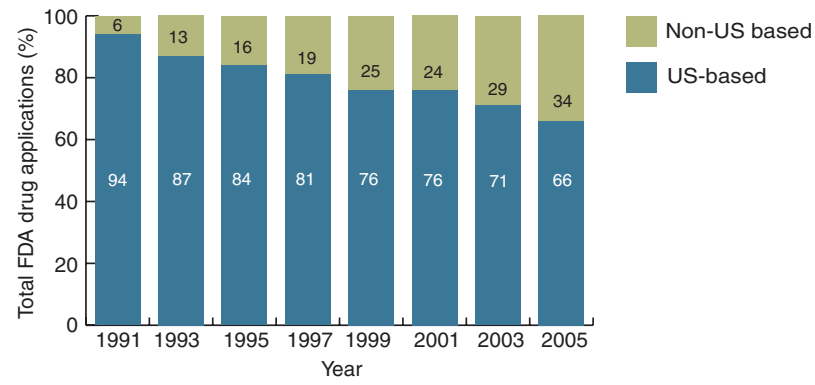

Source: Food and Drug Administration; Tufts Center for the Study of Drug Development

\section{Number of drugs in clinical trials in Europe}

Most of the late-stage drug trials in Europe are concentrated in the UK, Germany and Switzerland.

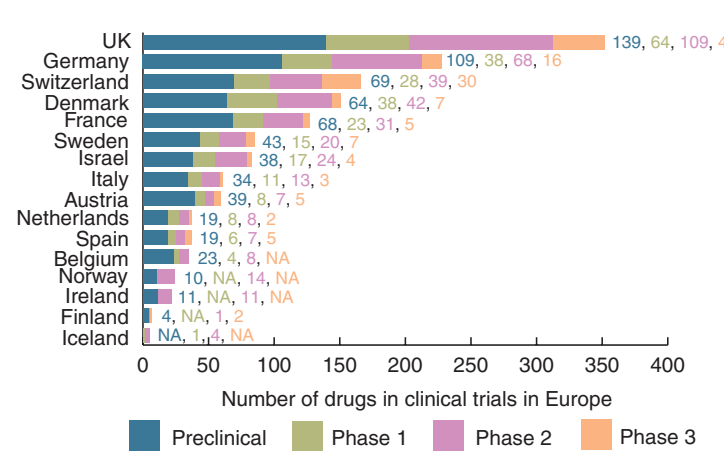

not only has pharma spending steadily increased but biotech firms also saw a jump in R\&D. The good news is that Investigational New Drug submissions and New Drug Applications continue to be above average, with the latter hitting a high not seen since 1999.

\section{FDA approval times for NMEs}

Last year, median approval times were relatively fast for both priority and standard FDA reviews.

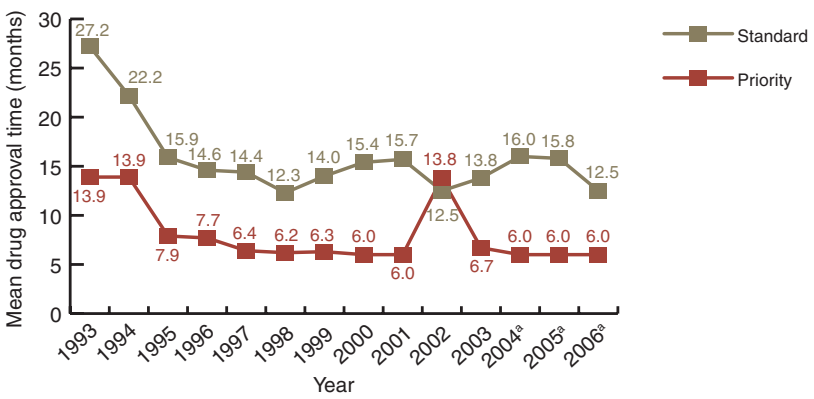

aIncludes biologics. NMEs, new molecular entities. Source: US Food and Drug Administration

\section{Approvals of small- and large-molecule therapeutics}

Since 2000, an average of about 19 small-molecule drugs have been approved each year compared with $\sim 6$ large molecules.

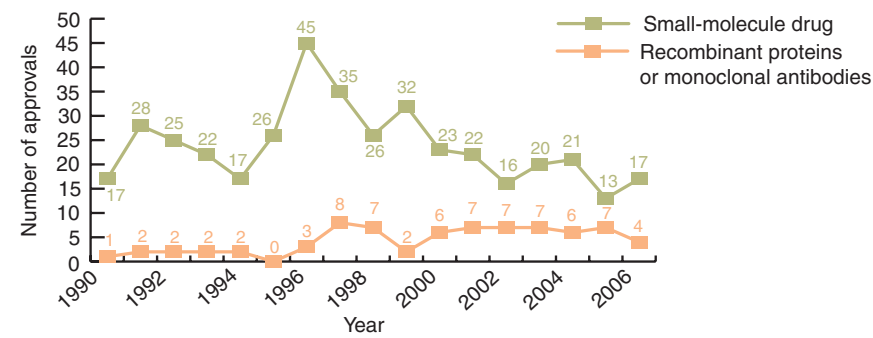

Based on FDA approvals. Source: Tufts Center for the Study of Drug Development

\section{Number of FDA applications}

Despite slight declines last year, investigational new drug (IND) submissions and new drug applications (NDA) are still up about one-third and one-fifth, respectively, from lows five or six years ago.

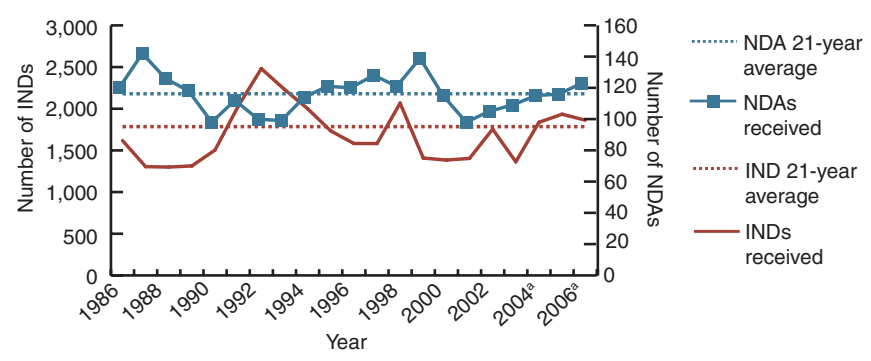

ancludes biologics. Source: Food and Drug Administration 